Research Article

\title{
Experiments on Mechanical Response and Energy Dissipation Behavior of Rockburst-Prone Coal Samples Under Impact Loading
}

\author{
Jinbao Tang, ${ }^{1}$ Sheng Li, ${ }^{1,2}$ Guangsheng Qin, ${ }^{3}$ Wanjie Lu, ${ }^{4}$ Zhijie Zhu $\left(\mathbb{D},{ }^{2}\right.$ Ce Jia, ${ }^{1}$ \\ Haiou Wen, ${ }^{1}$ and Lei Yang \\ ${ }^{1}$ College of Mining, Liaoning Technical University, Fuxin, China \\ ${ }^{2}$ State Key Laboratory of Mining Disaster Prevention and Control Co-Founded by Shandong Province and the Ministry of Science \\ and Technology, Shandong University of Science and Technology, Qingdao, China \\ ${ }^{3}$ Fuxin Hongdikan New Energy Co., Ltd, Fuxin, Liaoning Province, China \\ ${ }^{4}$ School of Mechanical Engineering, Liaoning Technical University, Fuxin, China \\ Correspondence should be addressed to Zhijie Zhu; zhuzhijie036@qq.com
}

Received 22 March 2021; Revised 16 April 2021; Accepted 3 May 2021; Published 11 May 2021

Academic Editor: chao xu

Copyright @ 2021 Jinbao Tang et al. This is an open access article distributed under the Creative Commons Attribution License, which permits unrestricted use, distribution, and reproduction in any medium, provided the original work is properly cited.

\begin{abstract}
To reveal the dynamic mechanical response and energy dissipation behavior of rockburst-prone coal samples under impact loading, the compressive experiments on Xinzhouyao coals (prone) and Machang coals (nonprone) under different impact loadings were carried out using the Split Hopkinson Pressure Bar (SHPB). The dynamic mechanical properties were studied, including dynamic elastic modulus, strain rate, peak stress, peak strain, dynamic increment factor, and energy dissipation. The results show that the dynamic elastic modulus, peak stress, and peak strain of both prone and nonprone coals perform an obvious correlation with the increase of strain rate. The strain rate strengthening effect on the dynamic elastic modulus and compressive strength of rockburst-prone coal samples are more significant, reflected by the greater increment with the increase of strain rate, while the dynamic increment factors of both prone and nonprone coals show apparent strain rate strengthening. The incident, reflected, and transmitted energy of both two coals linearly increases with the impact velocity, although the increased rate may be different. The dissipated energy of rockburst-prone coal samples increases faster, while the rate of the increase of the dissipated energy is more stable with strain rate. The results may provide an important reference for revealing the failure law of engineeringscaled coal mass suffered by rockburst.
\end{abstract}

\section{Introduction}

Coal and rock mass buried in deep is subjected to a complex geological environment with the depletion of shallow resources and the increase of coal mining depth $[1,2]$. Coal mass with great stored elastic energy may be subjected to strong impact loading when it is disturbed by mining operations, such as uncovering coal seam from rock mass, engineering blasting, roadway excavation, nearby coal seam mining, resulting in serious mine dynamic disasters such as rockburst, coal and gas outburst accompanyed with a large amount of released energy [3-9]. These disasters may lead to great property losses and casualties. Therefore, it is much significant to reveal the dynamic mechanical response of coal and rock mass under different impact loadings and the law of energy dissipation in the process of dynamic failure, which may provide a reliable theoretical basis for further understanding of the trigger mechanism of dynamic disasters [10].

Kolsky first proposed the Split Hopkinson Pressure Bar (SHPB) system in 1949 to investigate the dynamic responses [11]. The SHPB tests are usually conducted to determine dynamic properties of brittle materials including concrete, ceramics, rocks, and coals, under a wide range of impact loadings or strain rates of $10^{-1} \sim 10^{-4} \mathrm{~s}^{-1}$ [12-15]. The coalrock mass under impact loading during coal mining and excavation will produce behavior dynamic responses with a high strain rate. These dynamic responses include the 
variation of density, wave velocity, porosity, strength, scale effect, bedding effect, water effect, and energy dissipation [16-20]. Klepaczko et al. studied the elastic and viscoelastic properties of Nova Scotia coal over a wide range of strain rates (quasistatic to impact) [21]. Zhao et al. studied on energy dissipation characteristics of coal samples under impact loading [22]. Wang et al. studied the effects of low temperature gradient on dynamic mechanical properties of coal through Split Hopkinson Pressure Bar (SHPB) dynamic impact experiment [23]. Li et al. analyzed the peak stress, the strain rate, dynamic elastic modulus, and failure characteristics of raw coal with three coring directions under the influence of five impact loads and structural anisotropy [24]. Liu et al. studied static and dynamic uniaxial compression tests on coal-rock considering the bedding directivity [25]. Cheng et al. and Zhang studied the mechanical property of gas coal under impact load [26, 27]. Gong et al. discovered the dynamic stress-strain curves of coal-rock combined body have a double-peak feature under a high loading rate range [28]. Li et al. studied dynamic damage characteristics of elastic and plastic combination coal under impact loading [29]. Zhao et al. and Feng et al. studied fractal characteristics of coal under impact loading [30, 31]. Moreover, many techniques have also been introduced to modify the SHPB system [32-34].

The above research has an important role in promoting the study of mechanical properties of coal and rock under impact loading. Extensive suites of dynamic SHPB tests have been carried on rock and common coal materials, but only a few such dynamic tests have been completed on rockburstprone coals. Most of these experiments only obtained the dynamic stress-strain curve. Here, we supplement this dearth of observations by recovering a full suite of dynamic failure characteristics and energy dissipation laws to contrast the response of rockburst-prone coals (Xinzhouyao coals) against a control sample of rockburst resistant coals (Machang coals) by using the Split Hopkinson Pressure Bar (SHPB) experimental system to reveal the mechanism of coal mine dynamic disasters induced by impact load.

\section{Experiments on the Dynamic Properties of Rockburst-Prone Coal under Impact Loading}

2.1. Coal Sample Preparation. One group of coals with rockbust proneness was taken from Xinzhouyao Coal Mine, Shanxi province. For comparison, another group of coals with nonproneness were collected from Machang Coal Mine, Guizhou province. The collected coal blocks are drilled and polished in the Mining Engineering Laboratory of Liaoning Technology University. According to the recommendation of the International Society of Rock Mechanics (ISRM), the sample size is $\varphi 50 \times 50 \mathrm{~mm}$ (diameter $\times$ length) with the flatness $(<0.5 \mathrm{~mm})$ and parallelism $(<0.02 \mathrm{~mm})$ of both ends. In this experiment, 36 coal samples were prepared, including 18 coal samples from Xinzhouyao Coal Mine and 18 coal samples from Machang Coal Mine. The measured static mechanical properties of coal samples are shown in Table 1.
2.2. Split Hopkinson Pressure Bar (SHPB) System. The SHPB system is composed of bullet, bullet velocimetry, incident bar, transmission bar, buffer bar, and damper, shown in Figure 1. The bullet is made of $\mathrm{Cr}$ alloy rigid with $37 \mathrm{~mm}$ in diameter and $300 \mathrm{~mm}$ in length. The incident and transmission bars are variable cross-section bars with $50 \mathrm{~mm}$ in diameter and $1200 \mathrm{~mm}$ in length. The diameter and length of the buffer bar are $50 \mathrm{~mm}$ and $1000 \mathrm{~mm}$, respectively. The stress wave velocity in the pressure bar is $5190 \mathrm{~m} / \mathrm{s}$, the elastic modulus is $210 \mathrm{GPa}$, and the density is $7.8 \times 10^{3} \mathrm{~kg} / \mathrm{m}^{3}$.

2.3. Basic Principles of the SHPB System. In the experiment, high pressure nitrogen is used to provide impact loading for the bullet. The bullet moving velocity is controlled by the pressure on the incident bar. When the elastic stress wave propagates to the interface between the specimen and the incident bar, the stress wave will reflect and transmit. At the same time, an electrical signal is formed. All electrical signals are collected by strain gauges at both ends of the incident and transmission bars and delivered to the data acquisition system.

Based on the one-dimensional stress wave theory, the collected strain signal is processed by the three-wave method to obtain the dynamic stress-strain relationship of coal samples [23]:

$$
\left\{\begin{array}{l}
\sigma_{s}(t)=\frac{E A}{2 A_{s}}\left[\varepsilon_{i}(t)+\varepsilon_{r}(t)+\varepsilon_{t}(t)\right] \\
\varepsilon_{s}(t)=\frac{C_{0}}{L} \int_{0}^{t}\left[\varepsilon_{i}(t)-\varepsilon_{r}(t)-\varepsilon_{t}(t)\right] \\
\dot{\varepsilon}_{s}(t)=\frac{C_{0}}{L}\left[\varepsilon_{i}(t)-\varepsilon_{r}(t)-\varepsilon_{t}(t)\right] .
\end{array}\right.
$$

where $\sigma_{s}(t), \varepsilon_{s}(t), \dot{\varepsilon}_{s}(t)$ are the dynamic stress, strain, and strain rate of coal samples respectively; $A$ and $A_{s}$ represent the cross-sectional area of the elastic bar and coal sample, respectively; $E$ represents the elastic modulus of the elastic bar; $C_{0}$ and $L$ represent the longitudinal wave velocity of the elastic bar and the length of the specimen, respectively; $\varepsilon_{i}(t)$, $\varepsilon_{r}(t), \varepsilon_{t}(t)$ represent the strain value of incident wave, reflected wave, and transmitted wave, respectively.

Let the cross-sectional area of the two bars be the same bar, the relation between the incident, reflected, and transmitted waver induced strain can be obtained :

$$
\varepsilon_{i}+\varepsilon_{r}=\varepsilon_{t} .
$$

Substituting equation (2) into equation (1), the basic principles of the SHPB experiment can be obtained:

$$
\left\{\begin{array}{l}
\sigma_{s}(t)=\frac{E A}{A_{s}} \varepsilon_{t}(t), \\
\varepsilon_{s}(t)=-2 \frac{C_{0}}{L} \int_{0}^{t} \varepsilon_{r}(t) \mathrm{d} t, \\
\dot{\varepsilon}_{s}(t)=-2 \frac{C_{0}}{L} \varepsilon_{r}(t) .
\end{array}\right.
$$


TABLE 1: Static mechanical properties of coal samples.

\begin{tabular}{|c|c|c|c|c|c|c|c|}
\hline $\begin{array}{l}\text { Sampling } \\
\text { location }\end{array}$ & $\begin{array}{l}\text { Uniaxial compressive } \\
\text { strength }(\mathrm{MPa})\end{array}$ & $\begin{array}{l}\text { Uniaxial tensile } \\
\text { strength }(\mathrm{MPa})\end{array}$ & $\begin{array}{c}\text { Elastic } \\
\text { modulus } \\
(\mathrm{GPa})\end{array}$ & $\begin{array}{l}\text { Poisson's } \\
\text { ratio }\end{array}$ & $\begin{array}{l}\text { Cohesion } \\
(\mathrm{MPa})\end{array}$ & $\begin{array}{l}\text { Friction } \\
\text { angle }\left({ }^{\circ}\right)\end{array}$ & Remarks \\
\hline $\begin{array}{l}\text { Xinzhouyao } \\
\text { coal }\end{array}$ & 30.19 & 1.34 & 3.66 & 0.20 & 3.67 & 29.89 & $\begin{array}{l}\text { Rockburst- } \\
\text { prone }\end{array}$ \\
\hline Machang coal & 17.73 & 0.70 & 0.85 & 0.15 & 0.51 & 37.55 & $\begin{array}{l}\text { Rockburst } \\
\text { nonprone }\end{array}$ \\
\hline
\end{tabular}

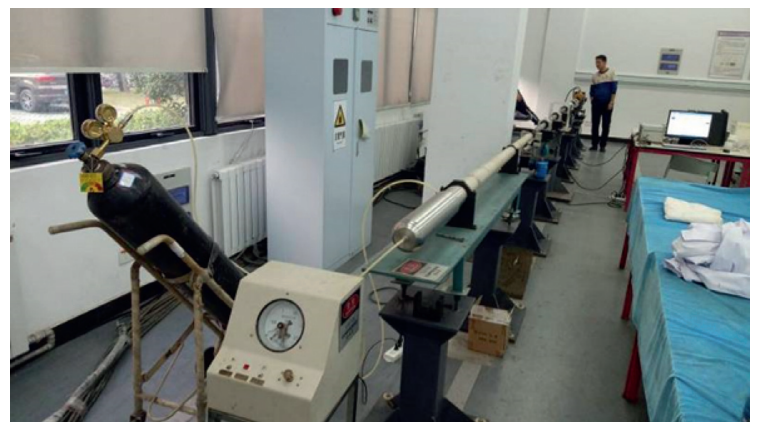

Figure 1: Photograph of the used Split Hopkinson Pressure Bar (SHPB) system.

The SHPB experiments involve five kinds of energies, including bullet carried energy, incident energy, reflected energy, transmitted energy, and dissipated energy. The incident, reflected, and transmitted energy of the test system can be expressed as follows [25]:

$$
\left\{\begin{array}{l}
W_{I}=\frac{A C}{E} \int_{0}^{t} \sigma_{i}^{2}(t) \mathrm{d} t=A C E \int_{0}^{t} \varepsilon_{i}^{2}(t) \mathrm{d} t \\
W_{R}=\frac{A C}{E} \int_{0}^{t} \sigma_{r}^{2}(t) \mathrm{d} t=A C E \int_{0}^{t} \varepsilon_{r}^{2}(t) \mathrm{d} t \\
W_{T}=\frac{A C}{E} \int_{0}^{t} \sigma_{t}^{2}(t) \mathrm{d} t=A C E \int_{0}^{t} \varepsilon_{t}^{2}(t) \mathrm{d} t
\end{array}\right.
$$

where $W_{I}, W_{R}, W_{T}$ are incident, reflected, and transmitted energy, respectively; $\sigma_{i}, \sigma_{r}, \sigma_{t}$ are the stress corresponding to the incident wave, reflected wave, and transmitted wave on the pressure bar, respectively; $\varepsilon_{i}, \varepsilon_{r}, \varepsilon_{t}$ are the strains corresponding to the stress of each stress wave on the pressure bar; $A$ is the cross-sectional area of pressure bar, $A=\pi r^{2}, r$ is $25 \mathrm{~mm}$; $E$ is the elastic modulus of the bar material, $210 \mathrm{GPa}$; $C$ is the stress wave velocity in the one-dimensional state, $C=\sqrt{E / \rho}, \rho$ is the material density of the pressure bar.

According to the mass conservation law, the energy dissipation in the failure process of coal sample $\left(W_{L}\right)$ can be expressed as follows:

$$
\begin{aligned}
W_{L} & =W_{I}-\left(W_{R}+W_{T}\right) \\
& =A C E \int_{0}^{t}\left\{\varepsilon_{i}^{2}(t)-\left[\varepsilon_{r}^{2}(t)+\varepsilon_{t}^{2}(t)\right]\right\} \mathrm{d} t .
\end{aligned}
$$

2.4. Experimental Design and Implementation. The nitrogen pressure provided by this experiment is $0.200 \mathrm{MPa}$, $0.225 \mathrm{MPa}, \quad 0.250 \mathrm{MPa}, \quad 0.275 \mathrm{MPa}, \quad 0.300 \mathrm{MPa}, \quad$ and $0.325 \mathrm{MPa}$. Repeat three times of each nitrogen pressure to ensure that the strain rate of the two groups of coal samples is consistent in the experiment. The variation law of incident velocity under different nitrogen pressures is shown in Table 2.

In order to ensure the stable transmission of the transmitted wave, the vaseline reagent was evenly smeared on both ends of the coal sample to keep it fully lubricated and coupled with the two bars, and the transverse strain caused by the difference in Poisson's ratio between the bar and the coal sample was eliminated. The coal sample is placed between the incident bar and the transmission bar, as shown in Figure 2.

\section{Dynamic Mechanical Characteristics of Rockburst-Prone Coal Samples}

3.1. Effect of Impact Velocity on Strain Rate. Figure 3 shows the relationship between the average strain rate of two groups of coal samples and the impact velocity of bullets. With the increase of impact velocity, the strain rate of both two groups of coal samples increases significantly. There is an intersection point between the curves of the two groups of coal samples because the rockburst-prone coal sample is harder. Under the low impact velocity, the strain rate will rise faster. The initial strain rate of nonprone coal samples is small, as there are numerous small cracks within the coal sample to undergo a compaction deformation process in nonprone coal samples. However, the average strain rate of the nonprone coal sample increases with the impact velocity when the impact velocity reaches $8.71 \mathrm{~m} / \mathrm{s}$, indicating that the impact velocity at this time is the critical value. Then, the strain rate will also increase with the impact velocity, which also meets the toughening effect of the impact velocity and the strain rate.

3.2. Dynamic Stress-Strain Curve. Because the stress-strain curves of coal samples show good similarity under the same strain rate, a typical stress-strain curve is selected for each strain rate in order to compare the stress-strain curves of coal samples at different strain rates more intuitively as shown in Figure 4. At the same time, the static stress-strain curves of coal sample are shown in Figure 5. It can be found 
TABLE 2: Variation of strain rate under different pressures.

\begin{tabular}{|c|c|c|c|c|c|}
\hline Sampling location & Numbering & $\begin{array}{l}\text { Average length } \\
(\mathrm{mm})\end{array}$ & $\begin{array}{l}\text { Diameter } \\
(\mathrm{mm})\end{array}$ & $\begin{array}{l}\text { Average nitrogen pressure } \\
\qquad(\mathrm{MPa})\end{array}$ & $\begin{array}{l}\text { Average incident } \\
\text { velocity }(\mathrm{m} / \mathrm{s})\end{array}$ \\
\hline \multirow{6}{*}{$\begin{array}{l}\text { Xinzhouyaocoal mine (rockburst- } \\
\text { prone) }\end{array}$} & $\mathrm{X}-1$ & 50.00 & 50 & 0.200 & 6.31 \\
\hline & $\mathrm{X}-2$ & 50.15 & 50 & 0.225 & 8.07 \\
\hline & $\mathrm{X}-3$ & 50.20 & 50 & 0.250 & 8.71 \\
\hline & $\mathrm{X}-4$ & 50.00 & 50 & 0.275 & 9.72 \\
\hline & $\mathrm{X}-5$ & 49.85 & 50 & 0.300 & 10.81 \\
\hline & $\mathrm{X}-6$ & 50.10 & 50 & 0.325 & 11.64 \\
\hline \multirow{6}{*}{$\begin{array}{l}\text { Machangcoal mine (rockburst } \\
\text { none-prone) }\end{array}$} & $\mathrm{Y}-1$ & 50.12 & 50 & 0.200 & 6.39 \\
\hline & $\mathrm{Y}-2$ & 51.05 & 50 & 0.225 & 7.97 \\
\hline & $\mathrm{Y}-3$ & 50.10 & 50 & 0.250 & 8.77 \\
\hline & $\mathrm{Y}-4$ & 50.13 & 50 & 0.275 & 9.75 \\
\hline & $\mathrm{Y}-5$ & 49.60 & 50 & 0.300 & 10.87 \\
\hline & Y-6 & 50.00 & 50 & 0.325 & 11.70 \\
\hline
\end{tabular}

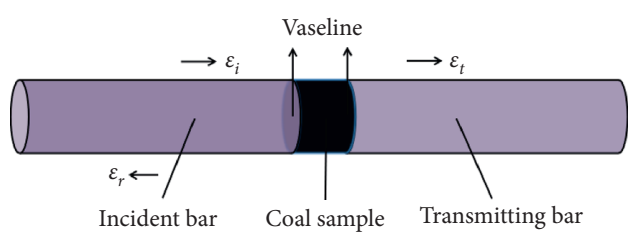

FIGURe 2: Picture of the placed coal sample and pressure bars.

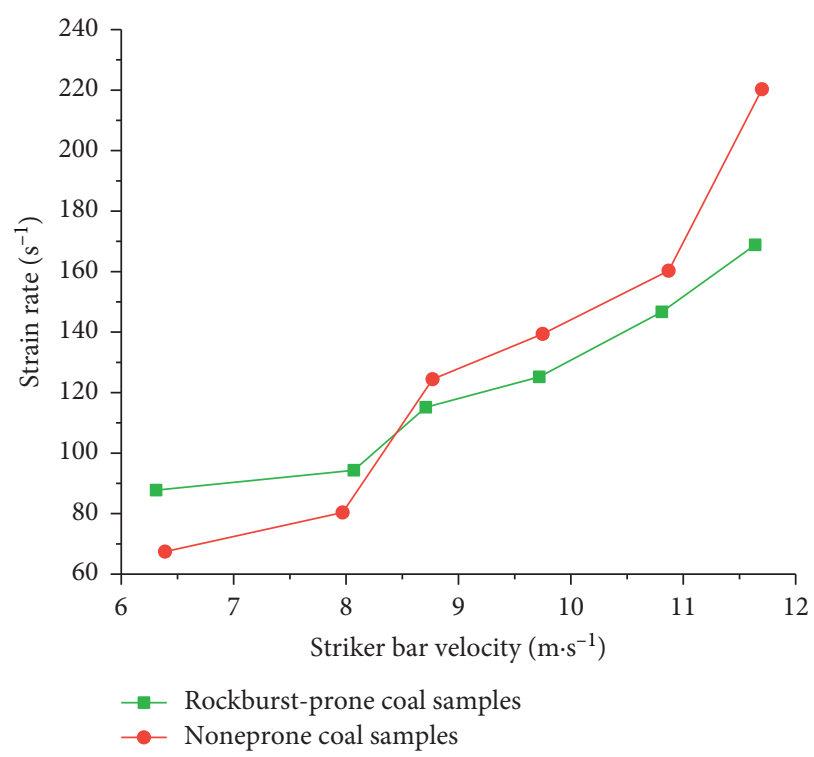

FIgURE 3: Relationship between impact velocity and strain rate.

that the static stress-strain relationship and the dynamic stress-strain relationship show obvious differences. The static stress-strain curve can be divided into four stages: compaction stage, elastic stage, plastic stage, and failure stage. The dynamic stress-strain curves of the two groups of coal samples are basically the same. The curve can be divided into five stages: the original nonlinear compaction stage, linear elastic stage, microfracture extension stage, plastic fracture propagation stage, and rapid unloading failure stage. The peak stress, peak strain, and elastic modulus can be extracted from the stress-strain curve of each coal sample. The basic mechanical parameters of the three coal samples at each strain rate are averaged in order to reduce the experimental error, and then the relationship between each mechanical parameter and the strain rate is analyzed.

3.3. Variation of Dynamic Elastic Modulus with Strain Rate. In order to reflect the difference of each coal sample and the change rule of the elastic modulus of the coal sample with the strain rate, the elastic modulus obtained from three repeated experiments at each strain rate is retained in the image, and the fitting curve of the average elastic modulus and the strain rate is made, as shown in Figure 6.

The dynamic elastic modulus of the two groups of coal samples increases with the strain rate, and the correlation between them is significant. The dynamic elastic modulus of rockburst-prone coal samples increases rapidly from $7.42 \mathrm{GPa}$ to $27.56 \mathrm{GPa}$, with the strain rate from $87.76 \mathrm{~s}^{-1}$ to $116.83 \mathrm{~s}^{-1}$, increased by 3.71 times, while the static elastic modulus of coal samples is $3.66 \mathrm{GPa}$, increased by 7.53 times. The dynamic elastic modulus of the nonprone coal samples increases from $1.14 \mathrm{GPa}$ to $2.34 \mathrm{GPa}$, increased by 2.05 times, and the static elastic modulus is $0.85 \mathrm{MPa}$ with 2.75 times of increment.

The relation between dynamic elastic modulus and strain rate of two groups of coal samples is fitted as follows:

$$
\begin{aligned}
E_{c 1} & =\exp (1.01163+0.01351 \dot{\varepsilon}), \\
R^{2} & =0.96066, \\
E_{c 2} & =\exp (-0.12356+0.00458 \dot{\varepsilon}), \\
R^{2} & =0.8909 .
\end{aligned}
$$

3.4. Variation of Peak Stress with Strain Rate. The relationship between strain rates and peak stress is shown in Figure 7. The same impact loading was applied on the two groups of coal samples. With the increase of strain rate, the peak stress of the rockburst-prone coal samples increases from $31.25 \mathrm{MPa}$ to $117.64 \mathrm{MPa}$, increased by 3.76 times. The peak stress increases from 19.24 MPa to $98.14 \mathrm{MPa}$, increased by 5.1 times, while the static peak stress is 17.73 MPa, increased by 5.54 times. The dynamic peak 


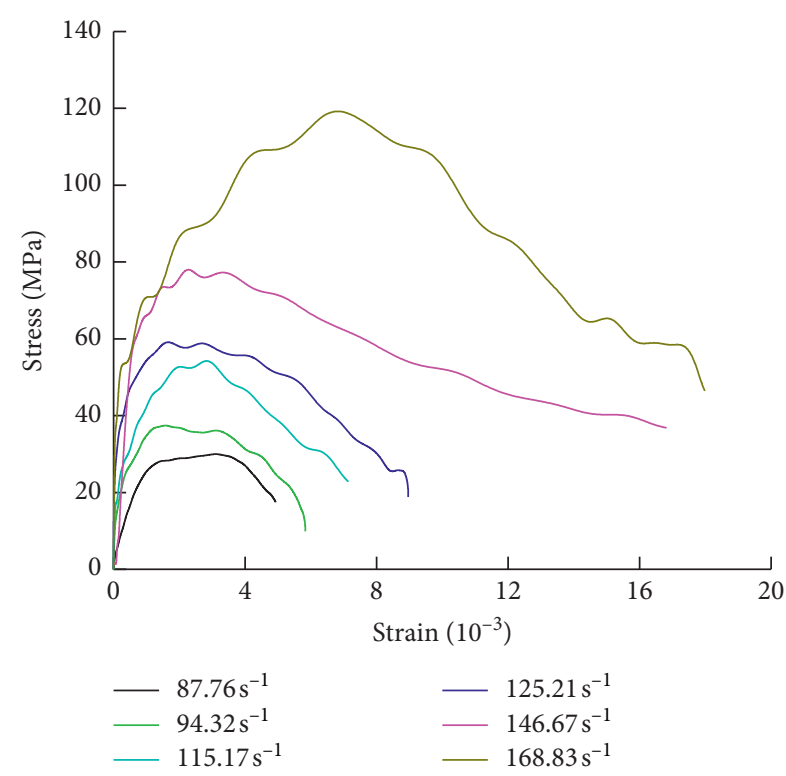

(a)

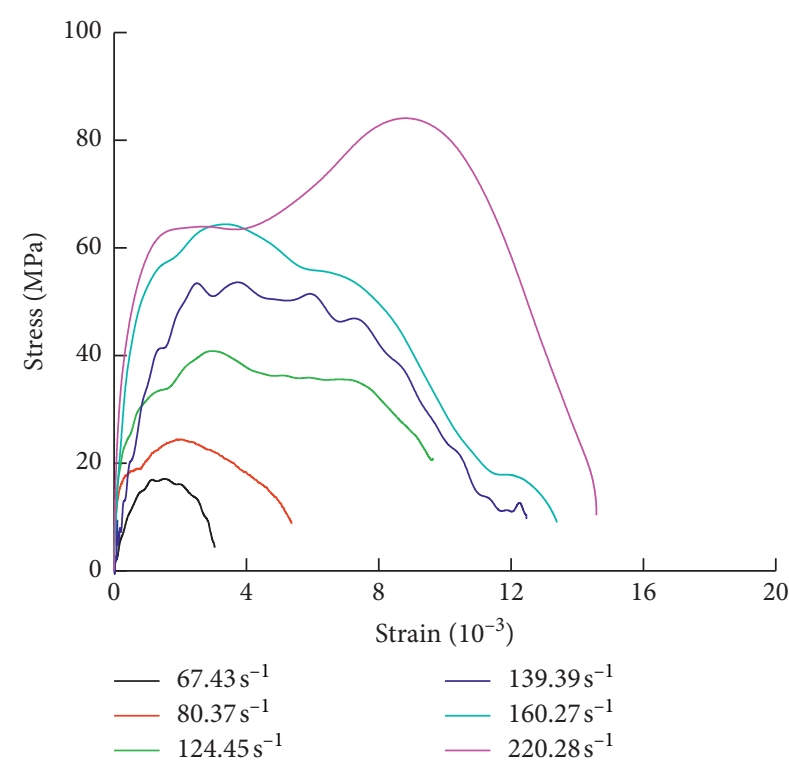

(b)

FIgURE 4: Dynamic stress-strain curve of coal samples under different strain rates. (a) Rockburst-prone coal samples. (b) Nonprone coal samples.

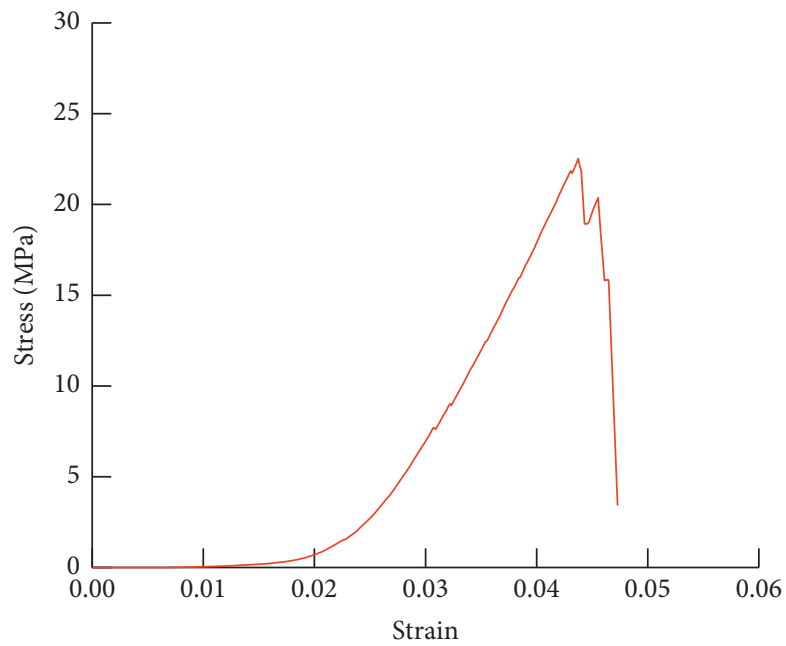

FIGURE 5: Static stress-strain curve of coal sample.

strain and strain rate of the two groups of coal samples increase approximately linearly in the range of $6.31 \sim 10.82 \mathrm{~m} / \mathrm{s}$. As the impact velocity reaches $11.64 \mathrm{~m} / \mathrm{s}$, the dynamic peak stress of outburst prone coal sample increases faster. The reason may be that there is a certain strain rate critical value in coal samples. When it exceeds this critical value, the internal stress accumulation rate of coal increases and the outburst prone coal seam is more likely to trigger a rockburst disaster. Relations between the dynamic peak stress and strain rate for the two groups of coal samples can be fitted as follows:

$$
\begin{aligned}
\sigma_{\max } & =\exp (2 \cdot 17724+0 \cdot 01523 \dot{\varepsilon}), \\
R^{2} & =0 \cdot 98772, \\
\sigma_{\max } & =\exp (2 \cdot 95076+0 \cdot 00777 \dot{\varepsilon}), \\
R^{2} & =0 \cdot 86095 .
\end{aligned}
$$

3.5. Variation of Peak Strain with Strain Rate. The relationship between peak strain and strain rate is shown in Figure 8 . The peak strain of rockburst-prone coal samples 


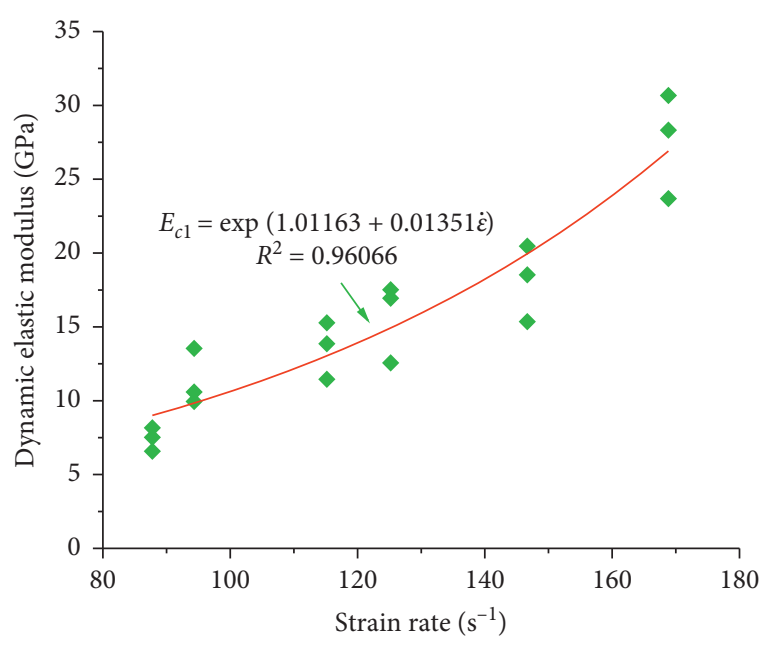

(a)

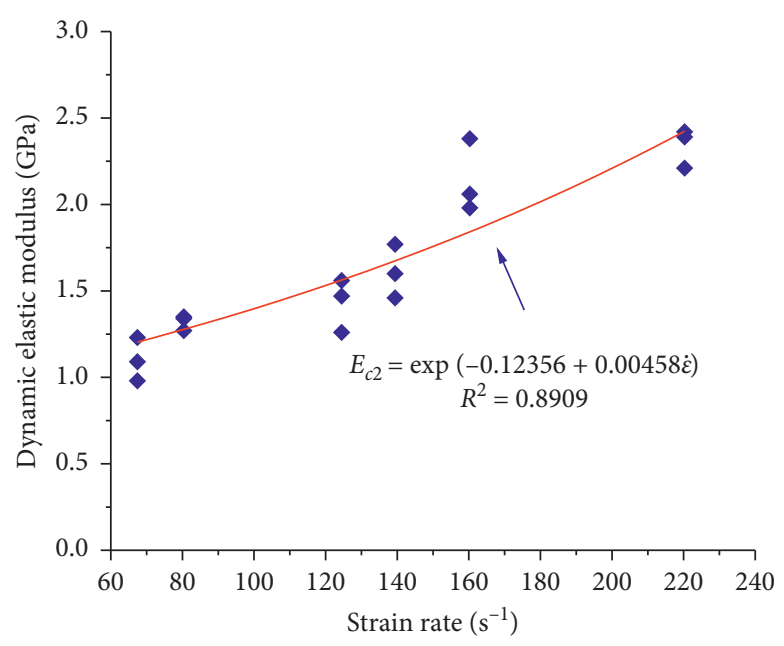

(b)

FIGURE 6: Relationship between dynamic elastic modulus and strain rate. (a) Rockburst-prone coal samples. (b) Nonprone coal samples.

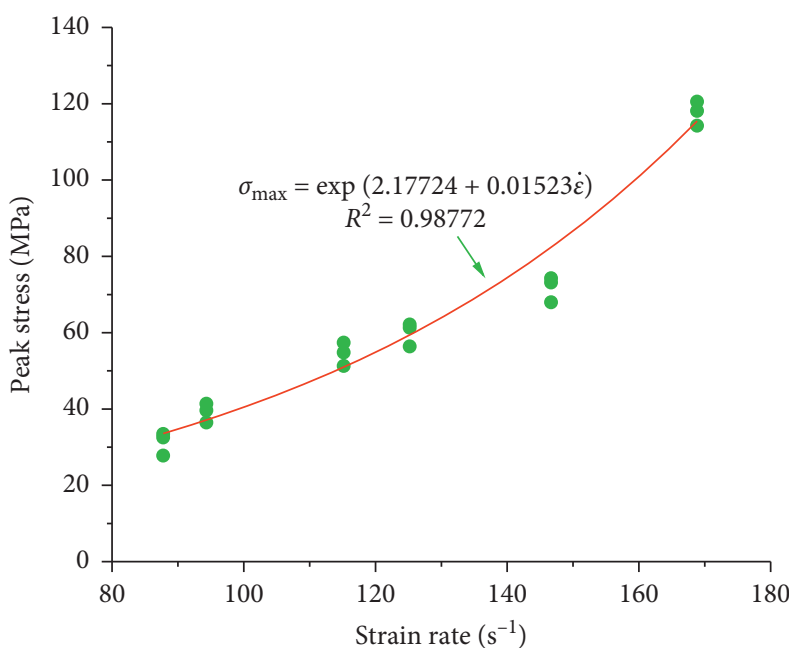

(a)

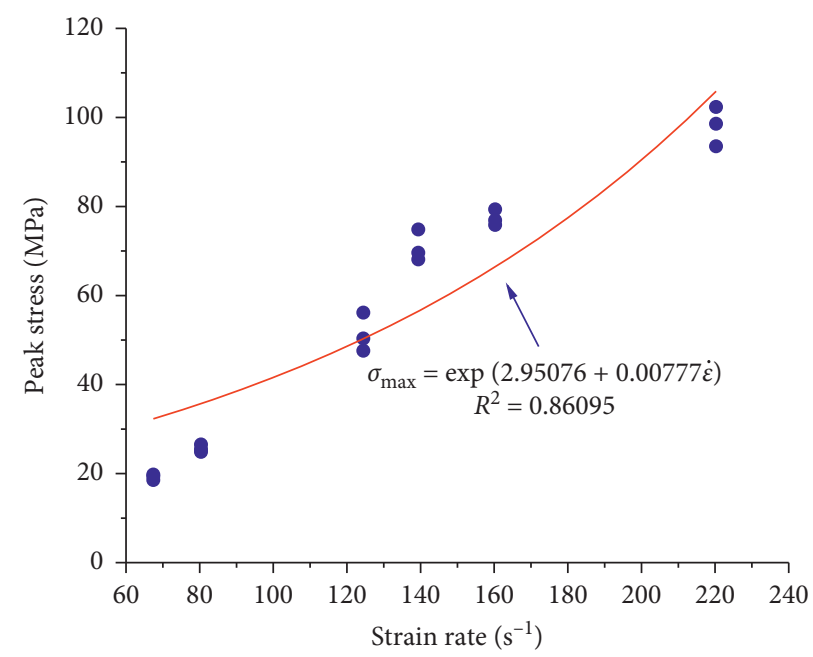

(b)

FIgURE 7: Relation between peak stress and strain rate. (a) Rockburst-prone coal samples. (b) Nonprone coal samples.

increases from $1.96 \times 10^{-3}$ to $7.73 \times 10^{-3}$ in the strain rate range of $87.76-168.83 \mathrm{~s}^{-1}$. Within the same strain rate range, the peak strain of nonprone coal samples increases from $1.31 \times 10^{-3}$ to $10.43 \times 10^{-3}$, showing an obvious increase with strain rate under dynamic compression. Because the nonprone coal samples are looser with a large number of internal cracks developed, the deformation needs an excessive time, and then the peak strain will increase with the strain rate at a faster speed. The relations between peak strain and strain rate of coal samples are fitted as follows:

$$
\begin{aligned}
\varepsilon_{\max } & =\exp (-1.21986+0.01901 \dot{\varepsilon}), \\
R^{2} & =0.92502, \\
\varepsilon_{\max } & =\exp (0.21157+0.00988 \dot{\varepsilon}), \\
R^{2} & =0.93678 .
\end{aligned}
$$

3.6. Relationship between Dynamic Increment Factor and Strain Rate. Dynamic increment factor (DIF) is the ratio of dynamic compressive strength to static compressive strength [24].

$$
\mathrm{DIF}=\frac{\sigma_{f}}{\sigma_{f s}},
$$

where $\sigma_{f}$ is the dynamic compressive strength of the coal sample, and $\sigma_{f s}$ is the static compressive strength of the coal samples.

The curves of dynamic increment factors of two groups of coal samples at different strain rates are shown in Figure 9. The DIF of rockburst-prone and nonprone coal samples show a significant strain rate increasing effect. Under the condition of low strain rate, the DIF of rockburst-prone coal samples rapidly increases, while the DIF of nonprone coal 


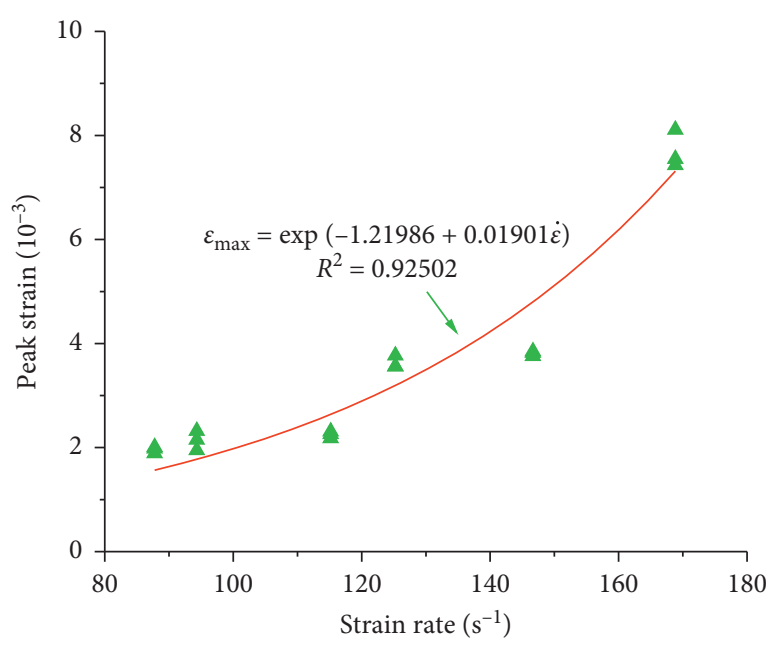

(a)

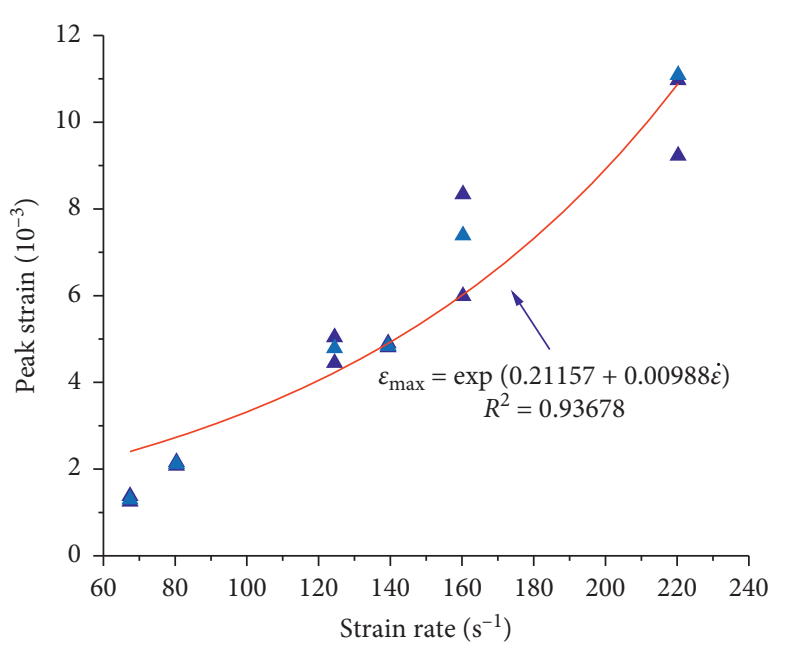

(b)

FIGURE 8: Variation of peak strain with strain rate. (a) Rockburst-prone coal samples. (b) Nonprone coal samples.

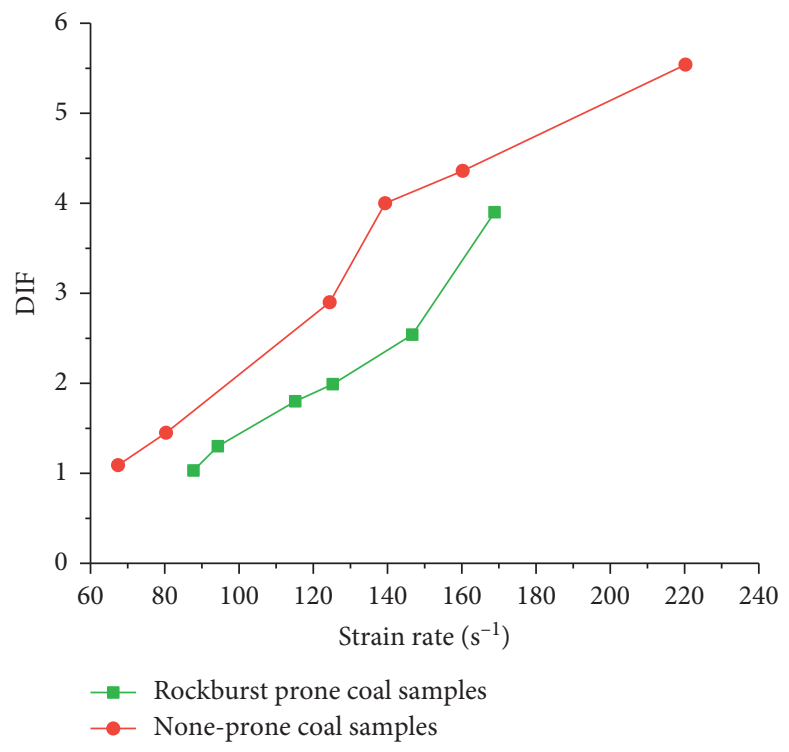

FIGURE 9: Relationship between dynamic increment factor and strain rate of coal samples.

samples increases more significantly, as well as the dynamic compressive strength.

\section{Energy Dissipation of Coal Failure under Impact Loading}

4.1. Effect of Impact Velocity on Stress Wave Energy. The variation of stress wave energy of coal samples with impact velocity is shown in Figure 10. The incident energy, reflected energy, and transmitted energy of both prone and nonprone coal samples grow significantly with the increase of impact velocity under impact loading. The incident energy of rockburst-prone coal samples increases from $73.65 \mathrm{~J}$ to $269.56 \mathrm{~J}$, with an increment of 3.66 times. The reflected energy increases from $62.56 \mathrm{~J}$ to $184.97 \mathrm{~J}$, with an increment of 2.96 times. The transmitted energy increases from $1.26 \mathrm{~J}$ to $2.15 \mathrm{~J}$, with an increment of 1.70 times. The incident energy of nonprone coal samples increases from $41.74 \mathrm{~J}$ to $471.43 \mathrm{~J}$, the reflected energy from $35.44 \mathrm{~J}$ to $392.05 \mathrm{~J}$, and the transmitted energy from $0.85 \mathrm{~J}$ to $1.48 \mathrm{~J}$ with an increase of $11.29,11.06$, and 1.74 times, respectively.

4.2. Variation of Dissipated Energy with Strain Rate. The curves of dissipated energy versus strain rate of both rockburst-prone and nonprone coal samples are shown in Figure 11. The dissipated energy for crushing coal samples rises rapidly with the increase of strain rate, showing a significant strain rate effect. The strain rate of rockburstprone coal samples is in the range of $87.76-168.83 \mathrm{~s}^{-1}$, and the dissipated energy increased from $9.83 \mathrm{~J}$ to $82.45 \mathrm{~J}$ by an increment of 8.39 times. The strain rate of the nonprone coal sample is in the range of $67.43-220.28 \mathrm{~s}^{-1}$, and the dissipated energy increases from $5.45 \mathrm{~J}$ to $77.90 \mathrm{~J}$ by an increment of 


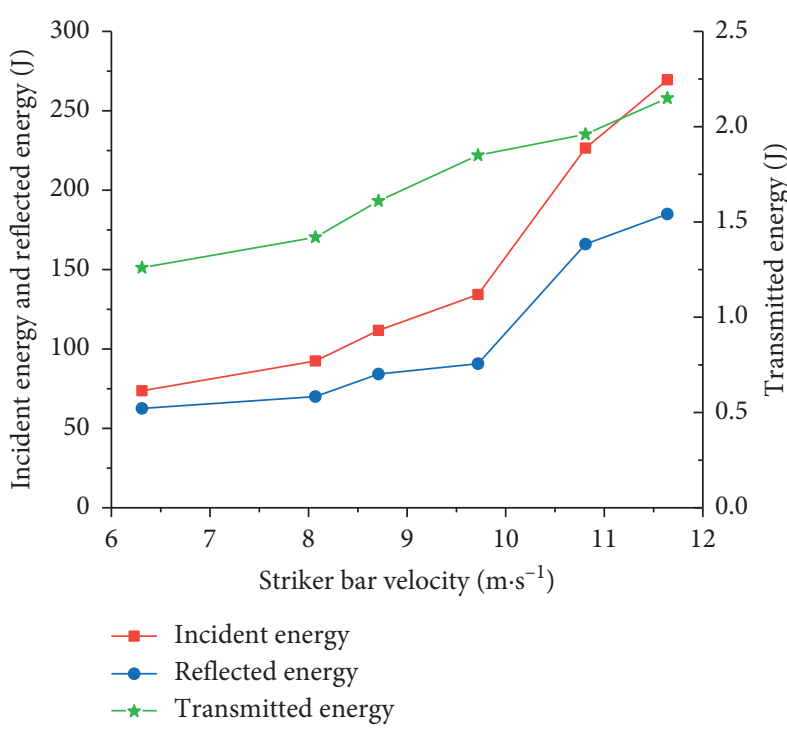

(a)

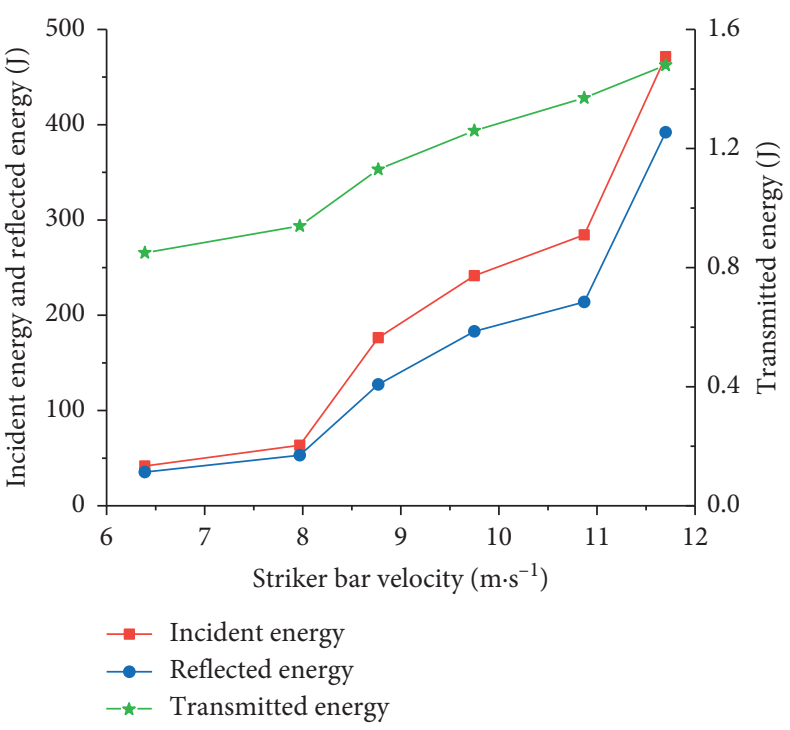

(b)

Figure 10: Relationship between stress wave energy and impact velocity. (a) Rockburst-prone coal samples. (b) Nonprone coal samples.

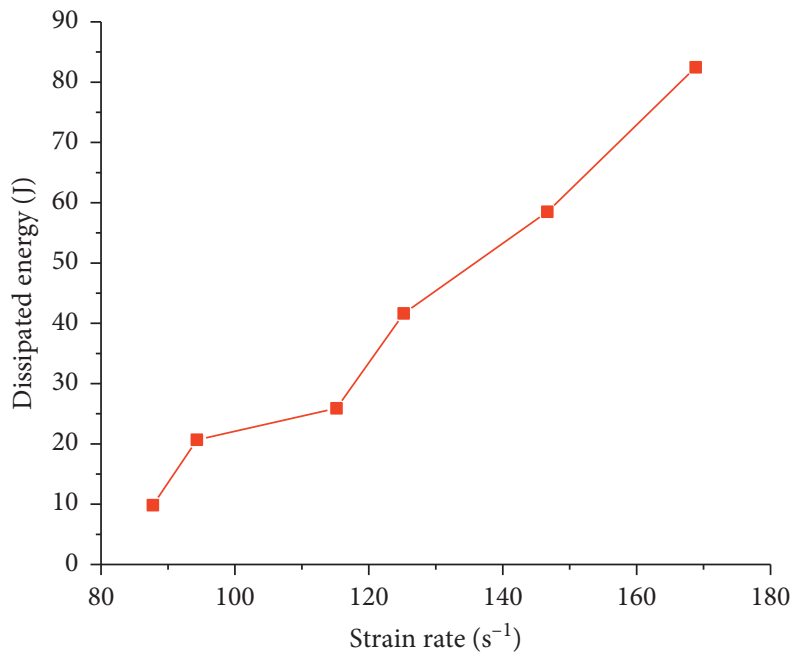

(a)

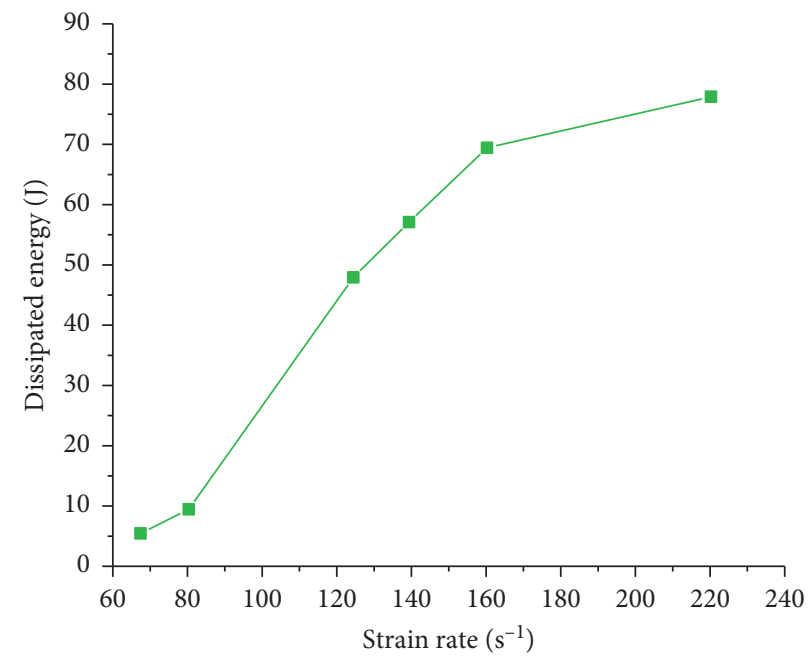

(b)

FIGURE 11: Variation of dissipated energy of coal samples with strain rate. (a) Rockburst-prone coal samples. (b) Nonprone coal samples.

14.29 times. With the increase of the strain rate, the original cracks of the coal sample could extend and develop, and new cracks would be generated, so the energy used for the destruction of the coal sample continues to increase. The dissipated energy of rockburst-prone coal sample grows faster, and the rate of the increase of the dissipated energy is more stable.

\section{Conclusions}

(1) The strain rate of both two groups of coal samples increases significantly with the increase of impact velocity, but there is a turning point in the strain rate change of the nonprone coal sample. The static stress-strain relationship and the dynamic stressstrain relationship show obvious differences. The dynamic stress-strain curve can be divided into four stages: the initial nonlinear compaction stage, the linear elastic stage, the microfracture evolution stage, the plastic fracturing stage, and the rapid unloading stage.

(2) The dynamic elastic modulus of coal samples increases with the increase of strain rate. However, the dynamic elastic modulus and strain rate strengthening characteristics of rockburst-prone coal samples are more significant. The peak stress and peak strain of both rockburst-prone and nonprone coal samples show an obvious increase effect with strain rate under impact loading.

(3) The dynamic increment factor (DIF) of all coal samples presents a significant strain rate effect. At a 
low strain rate, the rate correlation between rockburst-prone and nonprone coal samples is similar. However, with the increase of strain rate, the strain rate strengthening of rockburst-prone coal is more significant.

(4) With the increase of impact velocity, the incident, reflected, and transmitted energy of both rockburstprone and nonprone coals increase with varying degrees. The energy of the rockburst-prone coal sample is more likely to be concentrated than that of nonprone coal sample, and the dissipated energy is greater with obvious strain rate correlation.

\section{Data Availability}

The experimental data used to support the findings of this study are included within the article.

\section{Conflicts of Interest}

The authors declare that they have no conflicts of interest.

\section{Acknowledgments}

This work was financially supported by the State Key Laboratory of Mining Disaster Prevention and Control, cofounded by Shandong Province and the Ministry of Science and Technology (MDPC201806); the National Natural Science Foundation of China (51874159 and 52074146).

\section{References}

[1] Z. Song, "Development status of mining engineering discipline in China and discussion on issues of its further development," Hazard Control in Tunnelling and Underground Engineering, vol. 1, no. 2, pp. 7-12, 2019.

[2] C. Fan, S. Li, M. Luo, W. Du, and Z. Yang, "Coal and gas outburst dynamic system," International Journal of Mining Science and Technology, vol. 27, no. 1, pp. 49-55, 2017.

[3] P. Małkowski and Z. Niedbalski, "A comprehensive geomechanical method for the assessment of rockburst hazards in underground mining," International Journal of Mining Science and Technology, vol. 30, no. 3, pp. 345-355, 2020.

[4] Z. Yang, C. Fan, T. Lan et al., "Dynamic mechanical and microstructural properties of outburst-prone coal based on compressive SHPB tests," Energies, vol. 12, no. 22, Article ID 4236, 2019.

[5] T. Lan, C. Fan, H. Zhang et al., "Seepage law of injected water in the coal seam to prevent rock burst based on coal and rock system energy," Advance in Civil Engineering, vol. 20189 pages, Article ID 8687108, 2018.

[6] Y. Zhao, H. Wang, S. Liu, Z. Mu, and Z. Lu, "Dynamic failure risk of coal pillar formed by irregular shape longwall face: a case study," International Journal of Mining Science and Technology, vol. 28, no. 5, pp. 775-781, 2018.

[7] C. Fan, S. Li, M. Luo, Z. Yang, and T. Lan, "Numerical simulation of hydraulic fracturing in coal seam for enhancing underground gas drainage," Energy Exploration \& Exploitation, vol. 37, no. 1, pp. 166-193, 2019.

[8] X. Ding, X.-C. Xiao, D. Wu, and X.-f. Lv, "Mechanical properties and charge signal characteristics in coal material failure under different loading paths," International Journal of Coal Science \& Technology, vol. 6, no. 2, pp. 138-149, 2019.

[9] D. Xue, J. Zhou, Y. Liu, and L. Gao, "On the excavationinduced stress drop in damaged coal considering a coupled yield and failure criterion," International Journal of Coal Science \& Technology, vol. 7, no. 5, pp. 58-67, 2020.

[10] C. Fan, S. Li, D. Elsworth, J. Han, and Z. Yang, "Experimental investigation on dynamic strength and energy dissipation characteristics of gas outburst-prone coal," Energy Science \& Engineering, vol. 8, no. 4, pp. 1015-1028, 2020.

[11] H. Kolsky, "An investigation of the mechanical properties of materials at very high rates of loading," Proceedings of the Physical Society. Section B, vol. 62, no. 11, pp. 676-700, 1949.

[12] X. Luo, J.-y. Xu, E.-l. Bai, and W. Li, "Research on the dynamic compressive test of highly fluidized geopolymer concrete," Construction and Building Materials, vol. 48, pp. 166-172, 2013.

[13] G. Ravichandran and G. Subhash, "Critical appraisal of limiting strain rates for compression testing of ceramics in a split Hopkinson pressure bar," Journal of the American Ceramic Society, vol. 77, no. 1, pp. 263-267, 1994.

[14] D. J. Frew, M. J. Forrestal, and W. Chen, "Pulse shaping techniques for testing brittle materials with a split hopkinson pressure bar," Experimental Mechanics, vol. 42, no. 1, pp. 93-106, 2002.

[15] M. Li, X. Mao, L. Cao, H. Pu, R. Mao, and A. Lu, "Effects of thermal treatment on the dynamic mechanical properties of coal measures sandstone," Rock Mechanics and Rock Engineering, vol. 49, no. 9, pp. 3525-3539, 2016.

[16] M. Costantino, "A computerized database for the mechanical properties of coal," Computers \& Geosciences, vol. 9, no. 1, pp. 53-58, 1983.

[17] Y. Zhao, S. Gong, X. Hao, Y. Peng, and Y. Ziang, "Effects of loading rate and bedding on the dynamic fracture toughness of coal: laboratory experiments," Engineering Fracture Mechanics, vol. 178, no. 1, pp. 375-391, 2017.

[18] X. Hau, W. Du, Y. Zhao et al., "Dynamic tensile behaviour and crack propagation of coal under coupled static-dynamic loading," International Journal of Mining Science and Technology, vol. 30, no. 5, pp. 659-668, 2020.

[19] X. Kong, S. Li, E. Wang et al., "Dynamics behaviour of gasbearing coal subjected to SHPB tests," Composite Structures, vol. 256, no. 1, Article ID 113088, 2021.

[20] Y. Wang and R. Yang, "Study of the dynamic fracture characteristics of coal with a bedding structure based on the NSCB impact test," Engineering Fracture Mechanics, vol. 184, no. 15, pp. 319-338, 2017.

[21] J. R. Klepaczko, T. R. Hsu, and M. N. Bassim, "Elastic and pseudoviscous properties of coal under quasi-static and impact loadings," Canadian Geotechnical Journal, vol. 21, no. 2, 1984.

[22] Y. X. Zhao, S. Gong, and Y. Q. Huang, "Experimental study on energy dissipation characteristics of coal samples under impact loading," Journal of China Coal Society, vol. 40, no. 10, pp. 2320-2326, 2015.

[23] Y. Wang, Y. Yang, Y. Zhang, and J. Wang, "Dynamic mechanical properties of coals subject to the low temperatureimpact load coupling effect," Scientific Reports, vol. 9, no. 1, Article ID 20218, 2019.

[24] M. Li, W. Liang, G. Yue, X. Zheng, and H. Liu, "Dynamic mechanical properties of structural anisotropic coal under low and medium strain rates," PLoS One, vol. 15, no. 8, Article ID e0236802, 2020. 
[25] X. Liu, F. Dai, R. Zhang, and L. Jianfeng, "Static and dynamic uniaxial compression tests on coal rock considering the bedding directivity," Environmental Earth Sciences, vol. 73, no. (10, pp. 5943-5949, 2015.

[26] X. Cheng, G. Zhao, Y. Li, X. Meng, Q. Tu, and C. Dong, "Experimental study on mechanical properties and energy dissipation of gas coal under dynamic and static loads," Deep Rock Behaviour in Engineering Environment, vol. 2020, Article ID 8815730, 14 pages, 2020.

[27] W. Zhang, Study on Mechanical Property of Soft Coal under Impact Load and its Effect to Coal and Gas Outburst, Anhui University of Science and Technology, Huainan, China, 2014.

[28] F. Gong, H. Ye, and Y. Luo, "The effect of high loading rate on the behaviour and mechanical properties of coal-rock combined body," Shock and Vibration, vol. 20189 pages, Article ID 4374530, 2018.

[29] F. Li, Y. Zhang, S. Fang et al., "Dynamic damage characteristics of elastic and plastic combination coal under impact loading," Journal of Mining \& Safety Engineering, vol. 33, no. 6, pp. 1102-1109, 2016.

[30] Y. Zhao, S. Gong, C. Zhang, Z. Zhang, and Y. Jiang, "Fractal characteristics of crack propagation in coal under impact loading," Fractals, vol. 26, no. 2, Article ID 1840014, 2018.

[31] J. Feng, E. Wang, Q. Huang, H. Deing, and Y. Ma, "Study on coal fractography under dynamic impact loading based on multifractal method," Fractals, vol. 28, no. 1, 2020.

[32] Y. Xu, "Numerical investigation of dynamic rock fracture toughness determination using a semi-circular bend specimen in Split Hopkinson Pressure Bar testing," Rock Mechanics and Rock Engineering, vol. 49, no. 3, pp. 731-745, 2016.

[33] C. W. Li, Q. Wang, and P. Lyu, "Study on electromagnetic radiation and mechanical characteristics of coal during an SHPB test," Journal of Geophysics \& Engineering, vol. 13, no. 3, pp. 391-398, 2016.

[34] X. Li, S. Chen, E. Wang, and Z. Li, "Rockburst mechanism in coal rock with structural surface and the microseismic (MS) and electromagnetic radiation (EMR) response," Engineering Failure Analysis, vol. 124, no. 6, Article ID 105396, 2021. 